\title{
Serum leukocyte cell-derived chemotaxin 2 level is associated with atopic dermatitis patients
}

\author{
Keyu Zhao ${ }^{1,2}$, Feng Xu ${ }^{2,3}$, Xinyu Jiang ${ }^{1,2}$, Jiong Chen ${ }^{3,4}$, Xiaoxia Zhu ${ }^{1}$, Qiongyan Zhou ${ }^{1}$, Suling Xu ${ }^{1}$ \\ ${ }^{1}$ Department of Dermatology, The Affiliated Hospital of Medical School, Ningbo University, Ningbo, China; ${ }^{2}$ Central Laboratory, The Affiliated \\ Hospital of Medical School, Ningbo University, Ningbo, China; ${ }^{3}$ State Key Laboratory for Managing Biotic and Chemical Threats to the Quality \\ and Safety of Agro-products, Ningbo University, Ningbo, China; ${ }^{4}$ Laboratory of Biochemistry and Molecular Biology, School of Marine Sciences, \\ Meishan Campus, Ningbo University, Ningbo, China \\ Contributions: (I) Conception and design: S Xu, J Chen; (II) Administrative support: S Xu, Q Zhou; (III) Provision of study materials or patients: X \\ Zhu; (IV) Collection and assembly of data: K Zhao, X Jiang; (V) Data analysis and interpretation: F Xu; (VI) Manuscript writing: All authors; (VII) \\ Final approval of manuscript: All authors. \\ Correspondence to: Dr. Suling Xu; Dr. Qiongyan Zhou. Department of dermatology, The Affiliated Hospital of Medical School, Ningbo University, \\ 247 Renmin Road, Ningbo 315000, China. Email: xusuling@nbu.edu.cn; zhou.qiongyan@163.com.
}

\begin{abstract}
Background Atopic dermatitis (AD) is a chronic skin inflammation with a heterogeneous immunological profile. Leukocyte cell-derived chemotaxin 2 (LECT2) is a liver-derived multifunctional cytokine that has been studied due to its important role in inflammatory and autoimmune diseases. However, the relationship between $\mathrm{AD}$ and LECT2 has not been defined. This study was performed to investigate the levels of LECT2 in patients with $\mathrm{AD}$ and to determine whether it was associated with the severity and clinical characteristics of $\mathrm{AD}$.

Methods: The study included 42 AD patients and 30 healthy controls from the Affiliated Hospital of Medical School of Ningbo University. Participants' serum levels of LECT2 were measured using enzymelinked immunosorbent assay kits. The values in the patient group and control group were statistically compared. The relationships between the different markers were evaluated by correlation analysis.

Results: The serum levels of LECT2 were significantly higher in AD patients than those in the controls. In addition, LECT2 was significantly correlated with the Scoring of Atopic Dermatitis (SCORAD) index, the level of immunoglobulin $\mathrm{E}(\mathrm{IgE})$, and eosinophils $(\mathrm{P}<0.01$, for all 3$)$.

Conclusions: Serum LECT2 levels were evaluated in AD patients. The results showed that LECT2 may be a useful biomarker of $\mathrm{AD}$, and may participate in the occurrence and regulation of inflammation in $\mathrm{AD}$ progression.
\end{abstract}

Keywords: Atopic dermatitis (AD); leukocyte cell-derived chemotaxin 2 (LECT2); cytokines; inflammatory factors

Submitted Sep 02, 2021. Accepted for publication Oct 16, 2021.

doi: 10.21037/apm-21-2690

View this article at: https://dx.doi.org/10.21037/apm-21-2690

\section{Introduction}

Atopic dermatitis (AD) is a common chronic relapsingremitting skin disorder mainly caused by complex interactions between eosinophils, mast cells, and activated T-helper $2\left(\mathrm{~T}_{\mathrm{h}} 2\right)$ lymphocytes (1). AD has a heterogeneous clinical presentation, and it is characterized by recurrent inflammatory eczematous lesions, intense pruritus and genetic specificity, which is different from common eczema (2). The prevalence of AD is continuously increasing globally in both children and adults, while effective treatments are still lacking (3). Patients diagnosed with $\mathrm{AD}$ are also at a high risk of developing asthma, allergic rhinitis, and food allergies, and could be at increased risk of a wide range of health and psychological outcomes, leading to a substantial psychosocial impact (4). Recently, a 
study showed that $\mathrm{AD}$ was mainly caused by biphasic $\mathrm{T}$-cell polarization (5), which implies strong activation of $T_{h} 2$ immune responses in lesions and even in nonlesional skin in the acute phase. Inflammatory factors such as interleukins 4 and 13 (IL- 4 and IL-13) are produced by $\mathrm{T}_{\mathrm{h}} 2$ cells during the pathogenesis of $A D$, while $T_{h} 17$ and $T_{h} 22$ also infiltrate the epidermis (6).

AD-related inflammatory factors were influenced by many cytokines such as signal transducer and activator of transcription 1 and 6 (STAT1, STAT6) (7) and thymic stromal lymphopoietin (TSLP) (8). Leukocyte cell-derived chemotaxin 2 (LECT2) is a liver-derived multifunctional cytokine (9). It has been identified as a neutrophil chemotactic protein, and it participates in many physiological and pathological processes such as hepatocarcinogenesis (10), bacterial sepsis (11), and nonalcoholic fatty liver disease (NAFLD) (12). As a liverproduced and blood-secreted protein, LECT2 was also found to be associated with autoimmune and chronic inflammation conditions such as atherosclerosis (13) and chronic gastritis (14). Previous studies found that LECT2 enhanced inflammation markers such as $І \kappa B$ phosphorylation (15), nuclear factor kappa-B (NF-кB) phosphorylation (13), and IL-6 expression (12). Additionally, it has been reported that a lack of LECT2 will activating Wnt/ $\beta$-catenin pathway, which will increase $\mathrm{T}$ Cell Factor1 (TCF1) and promotes differentiation into the $T_{h} 2$, thus increase the level of IL-4 (15). These results suggest complex interactions between LECT2 and the development of inflammation. Because LECT2 is correlated with several autoimmune and chronic inflammatory diseases, we hypothesize that LECT2 may affect the development of $\mathrm{AD}$, a chronic inflammatory condition induced by $\mathrm{T}_{\mathrm{h}} 2$ lymphocytes. And LECT2 may be associated with specific clinical indexes of $\mathrm{AD}$, such as $\mathrm{IgE}$ and eosinophil. These two indexes played important roles in the pathology and diagnosis of $\mathrm{AD}$ (3). As the clinical significance of serum LECT2 levels in AD patients has rarely been studied and the specific role of LECT2 in $T_{h} 2$ inflammatory disease is still unclear, in this study, we evaluated the levels of serum LECT2 in AD patients and healthy subjects. Additionally, the relationships between serum LECT2 level and specific clinical indexes such as level of $\mathrm{IgE}$, eosinophil, and SCORAD index in $\mathrm{AD}$ patients were also investigated.

We present the following article in accordance with the STROBE reporting checklist (available at https://dx.doi. org/10.21037/apm-21-2690).

\section{Methods}

\section{Patient data}

A total of 72 participants were enrolled in this study, including $42 \mathrm{AD}$ patients and 30 healthy subjects. All subjects were enrolled consecutively in the Allergy and Pediatric Surgery Outpatient Clinic at the Affiliated Hospital of Medical School, Ningbo University, during June 2020 to March 2021. Patients with another dermatitis or allergic disease such as urticaria, drug eruption, food allergy, asthma, or rhinitis were excluded. An informed consent form was obtained from each study subject. The data of clinical parameters [including serum immunoglobulin E (IgE), total eosinophils, and C-reactive protein] and demographic features (including age, gender, and family history of allergy) were collected from patient files. The SCORAD index was used to evaluate the clinical classification of skin severity of these $\mathrm{AD}$ patients. All procedures performed in this study involving human participants were in accordance with the Declaration of Helsinki (as revised in 2013). The study was approved by Ethics Committee of the Affiliated Hospital of Medical School, Ningbo University (No. KY20191208) and informed consent was taken from all the patients.

\section{Blood collection}

Blood samples of $\mathrm{AD}$ patients and healthy controls were collected from the clinical lab of the Affiliated Hospital of Medical School, Ningbo University. Serum separation was performed after centrifugation of Ethylene Diamine Tetraacetic Acid (EDTA) whole blood samples at 12,000 g for 15 minutes. All samples were subpackaged and stored at $-80{ }^{\circ} \mathrm{C}$ until use.

\section{ELISA}

Serum samples from the AD and control groups were used to measure the level of LECT2 using a commercially available human LECT2 enzyme-linked immunosorbent assay (ELISA) kit (CUSABIO, Wuhan, China). All experiments were performed according to the manufacturer's protocol. The results were analyzed using a Thermo MK3 microplate reader at $490 \mathrm{~nm}$.

\section{Statistical analysis}

All data were input in the computer and statistically analyzed 
Table 1 Clinical and metabolic data of AD patients and healthy controls

\begin{tabular}{lccc}
\hline Parameter & AD $(n=42)$ & Control $(n=30)$ & $P$ \\
\hline Age in years & $4.13 \pm 5.00$ & $3.45 \pm 2.08$ & 0.483 \\
Male/female & $23 / 19$ & $16 / 14$ & 0.905 \\
hsCRP & $1.71 \pm 3.70$ & $0.55 \pm 0.89$ & 0.110 \\
Absolute value of eosinophils & $0.60 \pm 0.45$ & $0.27 \pm 0.21$ & $0.001^{*}$ \\
Eosinophil (\%) & $6.54 \pm 4.17$ & $3.26 \pm 2.29$ & $0.00001^{*}$ \\
IgE & $364.92 \pm 844.18$ & & \\
SCORAD score & $39.69 \pm 11.94$ & & \\
\hline
\end{tabular}

${ }^{*}$, significant. AD, atopic dermatitis; hsCRP, high-sensitivity C-reactive protein.

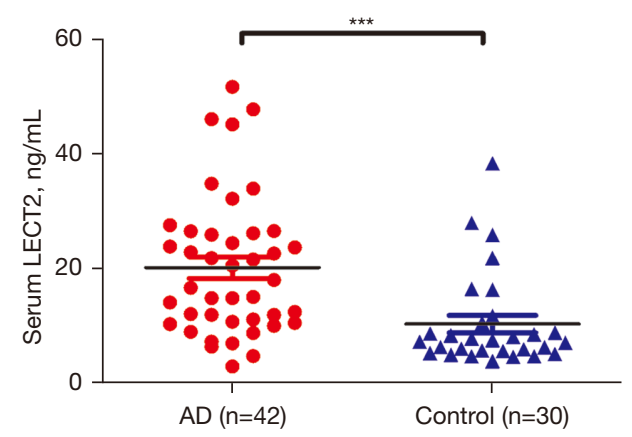

Figure 1 Comparison of serum LECT2 levels in $\mathrm{AD}$ patients and healthy controls. The levels of serum LECT2 were significantly higher in AD patients $(n=42)$ than in healthy controls $(n=30$, $\mathrm{P}<0.001)$. ${ }^{* * *}$, significant. $\mathrm{AD}$, atopic dermatitis; LECT2, leukocyte cell-derived chemotaxin 2 .

using IBM SPSS Statistics Version 25.0 (IBM, New York, USA) and GraphPad Prism 8.0 (GraphPad Software, San Diego, CA, USA). The continuous variables were analyzed using Student's $t$-test. Statistical comparison of the 2 groups was presented as mean \pm SD by the Mann-Whitney $U$ test or Student's $t$-test. The correlation between 2 variables was assessed using the Spearman rank correlation coefficient. P values less than 0.05 were considered statistically significant.

\section{Results}

\section{Clinical and metabolic data of AD patients and healthy controls}

The general characteristics of $\mathrm{AD}$ patients and healthy controls are summarized in Table 1 . There were $42 \mathrm{AD}$ patients (23 males and 19 females, age: $4.13 \pm 5.00$ years) and 30 healthy controls (16 males and 14 females, age: 3.45 \pm 2.08 years). No significant difference was observed between the 2 groups in terms of age and gender. The mean level of serum $\operatorname{IgE}$ in $\mathrm{AD}$ patients was $364.92 \pm 844.18 \mathrm{IU} / \mathrm{mL}$ and the mean SCORAD index was 39.69 \pm 11.94 .

\section{Serum LECT2 were significantly higher in AD patients}

A significant difference was found in serum LECT2 levels between $\mathrm{AD}$ patients and the control group. The statistical analysis showed that serum LECT2 levels of the $\mathrm{AD}$ group were significantly higher than those of the control group (20.26 \pm 16.08 vs. $10.48 \pm 8.12 \mathrm{ng} / \mathrm{mL}, \mathrm{P}<0.001$; Figure 1).

\section{Serum LECT2 were related with SCORAD severity score and IgE}

Based on the SCORAD index, a total of $42 \mathrm{AD}$ patients were divided into 3 groups: mild $(n=5)$, moderate $(n=29)$, and severe $(n=8)$. A significant difference was found in the levels of serum LECT2 between the 3 subgroups separated by the SCORAD severity score $(\mathrm{P}<0.001$, Table 2$)$. The correlation between the levels of serum LECT2 and the SCORAD index of $\mathrm{AD}$ patients was also assessed. The levels of serum LECT2 were highly associated with the SCORAD index of $\mathrm{AD}$ patients $\left(\mathrm{R}^{2}=0.642, \mathrm{P}<0.001\right.$; Figure $\left.2 A\right)$ and the level of serum $\operatorname{IgE}\left(\mathrm{R}^{2}=0.153, \mathrm{P}=0.011\right.$; Figure $\left.2 B\right)$.

\section{Serum LECT2 were related with eosinophil levels of AD patients}

Additionally, the relationships between the levels of serum LECT2 and eosinophil levels of AD patients (eosinophil 
Table 2 Serum LECT2 levels according to the SCORAD index

\begin{tabular}{lccc}
\hline SCORAD index & Mild $(n=5)$ & Moderate $(n=29)$ & Severe $(n=8)$ \\
\hline Serum LECT2 $(\mathrm{ng} / \mathrm{mL})$ & $12.66 \pm 8.53$ & $16.80 \pm 7.89$ & $37.52 \pm 11.52$ \\
\hline
\end{tabular}

*, significant. LECT2, leukocyte cell-derived chemotaxin 2.
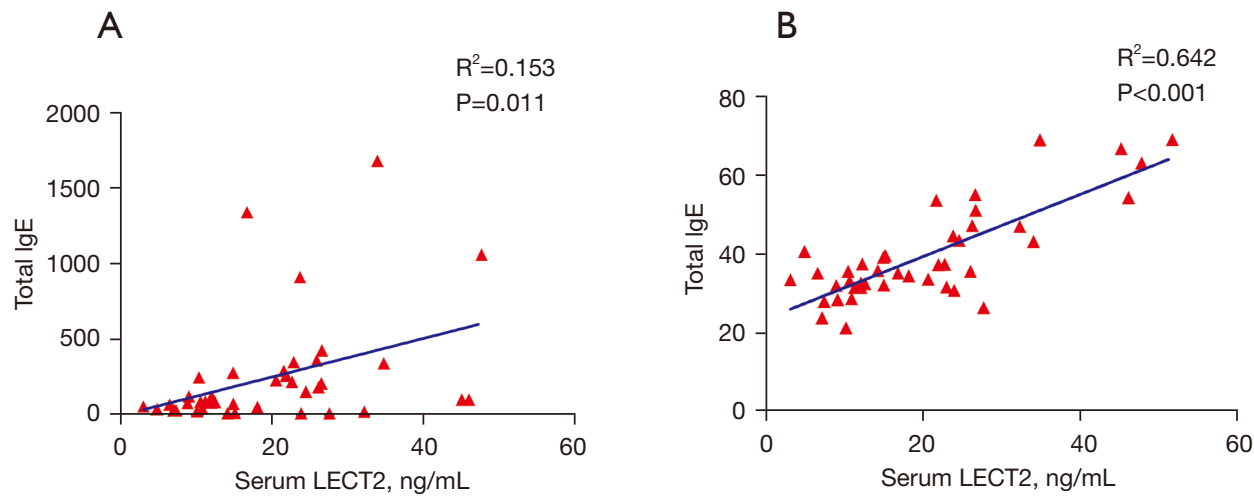

Figure 2 Correlation of LECT2 with (A) total IgE and (B) the SCORAD index of patients. The levels of serum LECT2 were significantly correlated with both total IgE and the SCORAD index of AD patients $(\mathrm{P}<0.05)$. AD, atopic dermatitis; LECT2, leukocyte cell-derived chemotaxin 2 .
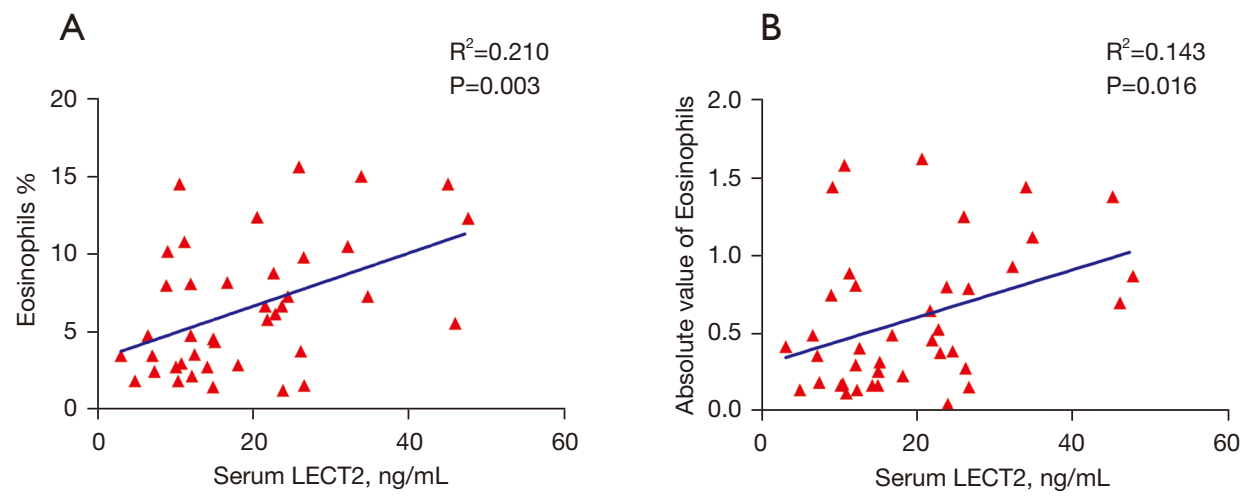

Figure 3 Correlation of LECT2 with AD patients' (A) eosinophil percentage and (B) absolute value of eosinophils. The levels of serum LECT2 were significantly correlated with both $\mathrm{AD}$ patients' eosinophil percentage and absolute value of eosinophils $(\mathrm{P}<0.05)$. $\mathrm{AD}$, atopic dermatitis; LECT2, leukocyte cell-derived chemotaxin 2.

percentage and the absolute value of eosinophils) were evaluated by Pearson correlation analysis. Interestingly, the results indicated that both the eosinophil percentage $\left(\mathrm{R}^{2}=0.210, \mathrm{P}=0.003\right.$; Figure $\left.3 A\right)$ and the absolute value of eosinophils $\left(\mathrm{R}^{2}=0.143, \mathrm{P}=0.016\right.$; Figure $\left.3 B\right)$ were significantly correlated with the serum levels of LECT2.

\section{Discussion}

LECT2, a type of chemotactic factor for neutrophils, was first found in phytohemagglutinin-activated human T-cell leukemia SKW-3 cells as an immunomodulatory factor (16). In recent years, studies have been focused on the 
relationships between LECT2 and inflammatory diseases. Lu et al. demonstrated that LECT2 treatment improved protective immunity in mouse bacterial sepsis and enhanced mouse phagocytosis and bacterial killing of macrophages directly through CD209a (11). He et al. showed that LECT2 inhibited the development of atherosclerosis, accompanied by reductions in inflammatory cytokines (13). Furthermore, Tanisawa et al. reported that participants with dyslipidemia had higher levels of plasma LECT2 than those without dyslipidemia (17). However, in NAFLD, overexpression of LECT2 led to more liver macrophage infiltration, and the inhibition of hepatic LECT2 expression alleviated high fat diet (HFD)-induced hepatic steatosis (12). LECT2 is also involved in many autoimmune-associated diseases including NAFLD (18), metabolic syndrome (19), and renal amyloidosis (20).

The present study was performed to determine the level of serum LECT2 in AD patients and to compare this with the healthy control group. Compared with heathy controls, the levels of serum LECT2 were significantly higher in the AD group. Furthermore, the levels of serum LECT2 were significantly correlated with the clinical data of $\mathrm{AD}$, especially with the SCORAD index of these AD patients. Our results showed that LECT2 levels were elevated in $\mathrm{AD}$ patients, which indicated that LECT2 might be useful as a diagnostic marker for $\mathrm{AD}$ and may be involved in the development of inflammation in $\mathrm{AD}$.

This study examined $42 \mathrm{AD}$ patients and 30 healthy participants, for whom, gender, and data of blood routine examination were gathered. As noted, the level of serum LECT2 was highly associated with the SCORAD index of AD patients. However, the SCORAD index also assesses xerosis, pruritus, and sleeplessness, and these differences may affect the accuracy of the index (21). Therefore, the index is mainly associated with skin lesion area. In lesional skin, Langerbans cells, which are inflammatory epidermal dendritic cells bearing specific $\operatorname{IgE}$ bound to the high affinity receptor for $\operatorname{IgE}$, and dermal dendritic cells take up allergens and antigens. The function of $\mathrm{IgE}$ in allergic inflammation suggests that $\operatorname{IgE}$ and $\mathrm{IgE}$-mediated mast cell and eosinophil activation contribute to $\mathrm{AD}$ (22). These cells can uptake as well as process allergens, and present the processed allergens to $\mathrm{T}$ cells resulting in $\mathrm{T}$ cell activation, leading to elevated levels of $\mathrm{T}_{\mathrm{h}} 2$ cytokines such as IL-4, IL5 , and IL-13. This means that a high level of serum LECT2 might also contribute to the migration of these $\mathrm{AD}$-related cells and result in the development of AD.

The specific pathogenetic role of LECT2 in the inflammatory processes which induce AD is still unknown. It is reported that $\mathrm{AD}$ is caused by immune dysfunction, leading to $\mathrm{IgE}$ sensitization and the outbreak of inflammatory factors (23). We believe that LECT2 may cause the occurrence of $\mathrm{AD}$ in many ways. LECT2 is associated with many inflammation-linked signaling pathways such as NF- $\kappa B$ and STAT1, among others $(12,13,15)$. NF- $\mathrm{KB}$ is an important transcriptional regulator that modulates the immune and inflammatory responses involved in the transcription of several targets (24). NF- $\kappa \mathrm{B}$ is also critical in the inflammatory response and mediates the activity of thymus and activation-regulated chemokine (TARC) in the skin inflammation of AD (25). The activity of TARC is involved in releasing $\mathrm{T}_{\mathrm{h}} 2$ type inflammationrelated cytokines such as IL-4, IL-5, and IL-13 (26). In addition, it has gradually become clear that $\mathrm{AD}$ is a kind of $\mathrm{T}_{\mathrm{h}} 2$ type chronic inflammation, which is mainly caused by elevated levels of IL-4 and IL-13, and LECT2 has been demonstrated to be correlated with IL-4 (27). Therefore, anti- $\mathrm{T}_{\mathrm{h}} 2$ type cytokine therapy including anti-IL-4 and IL13 has been a useful strategy for $\mathrm{AD}$ treatment, and LECT2 may be a potential therapeutic target of $\mathrm{AD}$.

Our study revealed the potential value of clinical application of LECT2 for diagnosis and treatment and of $\mathrm{AD}$. LECT2 may promote protective immunity against $\mathrm{AD}$ and reduce the level of $\mathrm{T}_{h} 2$ cytokines and the inflammation of $\mathrm{AD}$ patients. Because of its multifunctional roles in various conditions, LECT2 is an attractive candidate for further investigation of its effect on treatment in AD. However, several limitations of our study should be mentioned. In this study, we haven't tested the expression of LECT2 in the skin of patients, because AD inspections are usually non-invasive and we haven't collected the skin sample. As a liver-produced and blood-secreted protein (13), the expression of LECT2 may be quite low in skin and LECT2 may influence the skin by specific receptor. And we haven't evaluated the relationship between LECT2 and all lymphocyte. This because eosinophils are mainly associated with the diagnosis and pathology of $\mathrm{AD}$ (3). The specific mode of action of LECT2 requires further research.

\section{Conclusions}

Our investigation demonstrated that serum LECT2 levels were higher in $\mathrm{AD}$ patients compared with healthy participants, which suggested that the serum LECT2 level could be a potential biomarker for AD. In addition, we found that the levels of serum LECT2 were highly 
associated with the IgE levels, SCORAD index, eosinophil percentage, and the absolute value of eosinophils in $\mathrm{AD}$ patients. These results indicate that LECT2 may participate in the occurrence and regulation of inflammation in $\mathrm{AD}$ progression. However, further large-scale prospective studies and research on the functional roles of LECT2 in the process of $\mathrm{AD}$ still need to be conducted.

\section{Acknowledgments}

Funding: This research was supported by The Foundation of Science and Technology Department of Zhejiang Province (No. 2018C37101), Zhejiang Provincial Natural Science Foundation of China under Grant (No. LY18H110003), The Major Science and Technology Program for Medicine and Health in Zhejiang Province (No. WKJ-ZJ-2012), and The Public Welfare Projects of Ningbo, China (No. 202002N3190). The funders of the study had no role in the study design, writing of the report, or the decision to submit the article for publication.

\section{Footnote}

Reporting Checklist: The authors have completed the STROBE reporting checklist. Available at https://dx.doi. org/10.21037/apm-21-2690

Data Sharing Statement: Available at https://dx.doi. org/10.21037/apm-21-2690

Conflicts of Interest: All authors have completed the ICMJE uniform disclosure form (available at https://dx.doi. org/10.21037/apm-21-2690). The authors have no conflicts of interest to declare.

Ethical Statement: The authors are accountable for all aspects of the work in ensuring that questions related to the accuracy or integrity of any part of the work are appropriately investigated and resolved. All procedures performed in this study involving human participants were in accordance with the Declaration of Helsinki (as revised in 2013). The study was approved by Ethics Committee of the Affiliated Hospital of Medical School, Ningbo University (NO.KY20191208) and informed consent was taken from all the patients.

Open Access Statement: This is an Open Access article distributed in accordance with the Creative Commons
Attribution-NonCommercial-NoDerivs 4.0 International License (CC BY-NC-ND 4.0), which permits the noncommercial replication and distribution of the article with the strict proviso that no changes or edits are made and the original work is properly cited (including links to both the formal publication through the relevant DOI and the license). See: https://creativecommons.org/licenses/by-nc-nd/4.0/.

\section{References}

1. Jin W, Huang $W$, Chen L, et al. Topical Application of JAK1/JAK2 Inhibitor Momelotinib Exhibits Significant Anti-Inflammatory Responses in DNCB-Induced Atopic Dermatitis Model Mice. Int J Mol Sci 2018;19:3973.

2. Langan $\mathrm{SM}$, Irvine $\mathrm{AD}$, Weidinger S. Atopic dermatitis. Lancet 2020;396:345-60.

3. Pavel AB, Renert-Yuval $\mathrm{Y}, \mathrm{Wu} J$, et al. Tape strips from early-onset pediatric atopic dermatitis highlight disease abnormalities in nonlesional skin. Allergy 2021;76:314-25.

4. Williams HC. Epidemiology of atopic dermatitis. Clin Exp Dermatol 2000;25:522-9.

5. Leonardi S, Cuppari C, Manti S, et al. Serum interleukin 17 , interleukin 23 , and interleukin 10 values in children with atopic eczema/dermatitis syndrome (AEDS): association with clinical severity and phenotype. Allergy Asthma Proc 2015;36:74-81.

6. Lee DY, Hwang CJ, Choi JY, et al. Inhibitory Effect of Carnosol on Phthalic Anhydride-Induced Atopic Dermatitis via Inhibition of STAT3. Biomol Ther (Seoul) 2017;25:535-44.

7. Clarysse K, Pfaff CM, Marquardt Y, et al. JAK1/3 inhibition preserves epidermal morphology in fullthickness 3D skin models of atopic dermatitis and psoriasis. J Eur Acad Dermatol Venereol 2019;33:367-75.

8. Wilson SR, Thé L, Batia LM, et al. The epithelial cellderived atopic dermatitis cytokine TSLP activates neurons to induce itch. Cell 2013;155:285-95.

9. Slowik V, Apte U. Leukocyte Cell-Derived Chemotaxin-2: It's Role in Pathophysiology and Future in Clinical Medicine. Clin Transl Sci 2017;10:249-59.

10. Benson MD, James S, Scott K, et al. Leukocyte chemotactic factor 2: A novel renal amyloid protein. Kidney Int 2008;74:218-22.

11. Lu XJ, Chen J, Yu CH, et al. LECT2 protects mice against bacterial sepsis by activating macrophages via the CD209a receptor. J Exp Med 2013;210:5-13.

12. Wang J, Chen Y, Pan R, et al. Leukocyte cell-derived chemotaxin 2 promotes the development of nonalcoholic 
fatty liver disease through STAT-1 pathway in mice. Liver Int 2021;41:777-87.

13. He WM, Dai T, Chen J, et al. Leukocyte cell-derived chemotaxin 2 inhibits development of atherosclerosis in mice. Zool Res 2019;40:317-23.

14. Shen HX, Li L, Chen Q, et al. LECT2 association with macrophage-mediated killing of Helicobacter pylori by activating $\mathrm{NF}-\kappa \mathrm{B}$ and nitric oxide production. Genet Mol Res 2016;15. doi: 10.4238/gmr15048889.

15. Jung TW, Chung YH, Kim HC, et al. LECT2 promotes inflammation and insulin resistance in adipocytes via P38 pathways. J Mol Endocrinol 2018;61:37-45.

16. Yamagoe S, Yamakawa Y, Matsuo Y, et al. Purification and primary amino acid sequence of a novel neutrophil chemotactic factor LECT2. Immunol Lett 1996;52:9-13.

17. Tanisawa K, Taniguchi H, Sun X, et al. Visceral fat area is a strong predictor of leukocyte cell-derived chemotaxin 2, a potential biomarker of dyslipidemia. PLoS One 2017;12:e0173310.

18. Okumura A, Saito T, Otani I, et al. Suppressive role of leukocyte cell-derived chemotaxin 2 in mouse anti-type II collagen antibody-induced arthritis. Arthritis Rheum 2008;58:413-21.

19. Mejia-Vilet JM, Cárdenas-Mastrascusa LR, PalaciosCebreros EJ, et al. LECT2 Amyloidosis in Kidney Transplantation: A Report of 5 Cases. Am J Kidney Dis 2019;74:563-6.

20. Chen CK, Yang CY, Hua KT, et al. Leukocyte cell-derived chemotaxin 2 antagonizes MET receptor activation to suppress hepatocellular carcinoma vascular invasion by

Cite this article as: Zhao K, Xu F, Jiang X, Chen J, Zhu X, Zhou Q, Xu S. Serum leukocyte cell-derived chemotaxin 2 level is associated with atopic dermatitis patients. Ann Palliat Med 2021;10(10):11006-11012. doi: 10.21037/apm-21-2690 protein tyrosine phosphatase $1 \mathrm{~B}$ recruitment. Hepatology 2014;59:974-85.

21. Chopra R, Vakharia PP, Sacotte R, et al. Severity strata for Eczema Area and Severity Index (EASI), modified EASI, Scoring Atopic Dermatitis (SCORAD), objective SCORAD, Atopic Dermatitis Severity Index and body surface area in adolescents and adults with atopic dermatitis. Br J Dermatol 2017;177:1316-21.

22. Liu FT, Goodarzi H, Chen HY. IgE, mast cells, and eosinophils in atopic dermatitis. Clin Rev Allergy Immunol 2011;41:298-310.

23. Czarnowicki T, Krueger JG, Guttman-Yassky E. Novel concepts of prevention and treatment of atopic dermatitis through barrier and immune manipulations with implications for the atopic march. J Allergy Clin Immunol 2017;139:1723-34.

24. Liu T, Zhang L, Joo D, et al. NF- $\kappa$ B signaling in inflammation. Signal Transduct Target Ther 2017;2:17023.

25. Choi JH, Lee GH, Jin SW, et al. Impressic Acid Ameliorates Atopic Dermatitis-Like Skin Lesions by Inhibiting ERK1/2-Mediated Phosphorylation of NF- $\kappa \mathrm{B}$ and STAT1. Int J Mol Sci 2021;22:2334.

26. Ma SQ, Wei HL, Zhang X. TLR2 regulates allergic airway inflammation through $\mathrm{NF}-\kappa \mathrm{B}$ and MAPK signaling pathways in asthmatic mice. Eur Rev Med Pharmacol Sci 2018;22:3138-46.

27. Saito T, Okumura A, Watanabe H, et al. Increase in hepatic NKT cells in leukocyte cell-derived chemotaxin 2-deficient mice contributes to severe concanavalin A-induced hepatitis. J Immunol 2004;173:579-85. 